\title{
Determinants of Access to Finance for Micro and Small Scale Enterprises in Nekemte Town
}

\author{
Kasahun Tamiru Tefera \\ Wollega University, Department of Accounting and Finance
}

\begin{abstract}
The objective of the study is to assess the determinants of access to finance by MSEs in Nekemte town using explanatory research design on the population of 22959 MSE firms of which 195 MSEs are computed as sample size. Simple random sampling technique is used to select the MSE firm operating in agriculture, construction, manufacturing, serves and trade sectors. Within the selected MSEs, operators with close information about MSE financing are selected for data collection using structured questionnaires and analyzed by SPSS 20 versions. The Binary logistic regression revealed operators education, MSE stage of growth, recording keeping, awareness of potential lenders and source of startup capital are significant determinants of access to finance. In conclusion, the finding reveled determinants of access to finance are observed from operators', MSE firm, management performance and financing institution related factors that need the collaborative effect of various stakeholders. The study recommend the provision of awareness, training, business planning and experience sharing for MSE owners by service provider and microfinance institutions are advised to be flexible in their loan terms, loan procedures and loan size for MSE firms.
\end{abstract}

Keywords: determinants, access to finance, micro enterprise, Nekemte, small enterprise

DOI: $10.7176 /$ RJFA/10-19-04

Publication date:October $31^{\text {st }} 2019$

\section{Introduction}

\subsection{Background of the Study}

In the past decades, the MSE sectors have given much attention by researcher and policy makers for their vital contributions to the world economy (Mahadalle \& Kaplan, 2017; Habtamu, 2015). MSEs are recognized in economic development, employment creation and income generation in all economies of the world (Balogun, Agumba, \& Ansary, 2016; Olawale, 2014; Kira \& He, 2012; Fatoki \& Smit, 2011).

The MSE businesses have been recognized as the seed bed for indigenous entrepreneurship and described as the natural home of entrepreneurship (Kusi, Opata, \& Narh, 2015). Also, the MSE business encourages diversification into new economic sectors and adapts foreign technologies to local markets (AfDB, OECD, \& UNDP, 2017).

In developing countries, MSEs are potential sources of employment and income generation (Kusi, Opata, \& Narh, 2015). The MSE contributes 45 percent to employment and 33 percent to annual Gross Domestic Product (GDP) in the year 2012 (Balogun, Agumba, \& Ansary, 2016; Nguyen \& Luu, 2013).

In this regard, Ethiopia has prioritized the development of the MSE sector for economic growth, employment generation and building of an industrial economy (Assefa, Zerfu, \& Tekle, 2014). The MSEs are the key component of industrial policy direction in urban areas with the key instruments of job creation (British Council, 2017; MoUDH, 2016) and the manufacturing sector become the key players in the development of potential investors (MoUDH, 2016).

The MSEs are the second largest employment generating for the poor households next to the agriculture sector (Mohammed, Habtamu, \& Dessalegn, 2014). The MSEs sector created an employment opportunity for about four million citizens between 2010 to 2014 in Ethiopia (UNDP, 2015) and serves as sources of income for lower level people (Tadesse, 2014).

The most economic constraints limiting MSEs from full contribution to the mainstream economy is lack of access to finance by MSEs (Balogun, Agumba, \& Ansary, 2016; Mohammed, Tsehai, Abebe, Tekle, Derbie, \& Degefa, 2015; Kira \& He, 2012). The MSEs in the world face challenge in finding financing sources (AfDB, OECD, \& UNDP, 2017; Hoang \& Otake, 2014) and access to finance is the major obstacle for most MSEs in developing economies (Peci, 2015; Williams, 2014; Nguyen \& Luu, 2013).

In Ethiopia, access to formal credit from Banks, Microfinance Institution (MFI) and saving and credit cooperatives are limited to 19 percent of loan for MSEs in the year 2015 (British Council, 2017). Thus, this study intends to assess determinants of access to finance by MSE found in Nekemte town.

\subsection{Statements of the Problem}

Due to lack of access to finance from formal financial institutions by MSE firms, the MSE owner tend to rely on internal sources of finance such as personal savings and funds from family and friends (Nawi, 2015). In Ethiopia, financial constraints (58\%) is the biggest challenge faced by MSEs in the form of debt or equity (British Council, 
2017; Assefa, Zerfu, \& Tekle, 2014) compared to normal business (20.3\%) identified finance as a major constraint (World Bank, 2014). Access to credit remains the challenge to start businesses and existing MSEs to expand their businesses (Mohammed, Tsehai, Abebe, Tekle, Derbie, \& Degefa, 2015).

When the result of the study conducted by (Mohammed, Tsehai, Abebe, Tekle, Derbie, \& Degefa, 2015) closely looked, the result of their study shows the existence of great variation in access to credit among major cities within different regional state of the country. Also, their study shows access to credit by MSEs from MFI in Adama town shows very low in provision of credit for MSE compared to other major cities found in another. The significant variation among major cities and the lowest level of access to credit in Adama town encourages an assessment of the supply side related challenges as determinants of access to finance by MSE firms.

In Ethiopia, the study by (Tadesse, 2014) found that inadequate loan size, high interest rate, poor book keeping systems, information gap about finance, fear of business failure, shortage of loan durations, failure to disburse loans timely and the tendency of group collateral requirements have been hampering MSEs from access to finance. In Oromiya region, 86 percent of enterprises have received no funding or financing from whatsoever sources (British Council, 2017). In Nekemte town, the study by (Goshu, 2016) found that the major source of finance for SMEs in Nekemte town was own source finance (52.6\%) and only 22.5 percent of MSEs accessed finance from financial institutions for their business indicating 77.5 of were lack access to finance. The study also revealed access to finance by MSEs was significant with firm size, owing of business plan, firm location, firm age and prevalence of corruption problem in Nekemte town.

However, most of the above studies were tried to investigate determinants of access to finance from firm side and from the side of MSE operators that determine MSE access to finance from the demand side. None of them are tried to access determinants of access to finance from the credit suppliers side such as MFI and banks. Thus, this study tried to fill the gaps on determinants of access to finance by MSEs using owners' factor, firms' factor, management performance and financial institutions related factors that determine access to finance by the MSE firms in Nekemte town of Oromia regional state.

\subsection{Research Questions}

In order to attain its objectives, this study will try to answer the following questions.

1. What are the MSE owners' related factors that affect access to finance by the MSE firms in Nekemte town?

2. What are financing institution related factors that affect access to finance by the MSE firms in Nekemte town?

\subsection{Objectives of the Study}

\subsubsection{General objective}

The general objective of the study is to assess determinants of access to finance for micro and small scale enterprises in Nekemte town.

1.4.2Specific objectives

Specifically, this study tries to:

$\checkmark \quad$ Identify the major owners' related factors (gender, education, experience and training) of MSE operators that affect access to finance by the MSE firms in Nekemte town;

$\checkmark$ Analyze financing institution related factors (collateral requirement, loan procedure and loan term) that affect access to finance by the MSE firms in Nekemte town.

\subsection{Significance of the Study}

The study is believed to have a number of significances. Principally, the result of the study contributes for the improvement of access to finance by the MSE firms. Also, as the study tried to assess determinants of access to finance by the MSE firms in Nekemte town, the result of the study may provide holistic picture of constraints of access to finance by the MSE firms.

\section{Empirical literature}

The principal sources of private sector debt for new MSEs are commercial banks and MFI (Olawale, 2014). In SSA, 59 percent of MSE operators fail to get access to credit compared to 31 percent in Central Asia and 34 percent in Latin America and the Caribbean (Legas, 2015). MSE's debt financing is a classic theme gaining attention by numerous scholars (Hoang \& Otake, 2014). Formal credit is debt financing where MSEs get finance products in a form of loan from lending institutions and give their promise to repay back at a given period of time (Osano \& Languitone, 2016). In Ethiopia, Banks, MFI and saving and credit associations are considered formal financial institutions that provide loan. Informal loans include money obtained from acquaintances, families and friends or social institutions including Iqubs (Mohammed, Tsehai, Abebe, Tekle, Derbie, \& Degefa, 2015).

Lending institutions in developing economies to MSEs are affected by information asymmetries between 
borrowers and lenders. This causes difficulties in obtaining external financing for startups and expansion potential (Abdesamed \& Wanab, 2014). Creditors use financial information provided by MSE firms to analyze their present performance and predict future performance (Asah \& Fatoki, 2011). Access to information is concerned with awareness of funding opportunities by MSEs (Osano \& Languitone, 2016). Lack of awareness about lending institutions hinders MSEs from access to credit (Hoang \& Otake, 2014).

Empirically, the study by (Asah \& Fatoki, 2011) found significant positive association between business information and access to finance by MSEs in South Africa. Also, the study by (Kira \& He, 2012) found that access to debt finance by MSE is positively and significantly determined by firms' business information in Tanzania. Similarly, the study by (Menike, 2015) found that that information asymmetry is an important significant determinant of access to finance by MSEs in Sri Lanka. Moreover, the study by (Osano \& Languitone, 2016) found a significant relationship between awareness of funding and access to finance by MSEs in Mozambique.

The traditional financial service providers have overly avoided taking risks in financing MSEs. The banking system in SSA plays a less prominent role in giving credit to firms than in other regions of the world (AfDB, OECD, \& UNDP, 2017). Microfinance Institutions (MFI) is an organization that provide microfinance services to entrepreneurs who have lack of access to formal financial services due to lack of financial or physical collateral (IMF, 2016). MFIs provide small loans, saving services, micro-insurance and money transfer services for the support of income generating activities (British Council, 2017; AfDB, OECD, \& UNDP, 2017). In Ethiopia, MFIs are the sole most important source of loans for MSEs (MoUDH, 2016), with other informal sources, such as family that playing a secondary role for MSEs (Mohammed, Tsehai, Abebe, Tekle, Derbie, \& Degefa, 2015).

Collateral is an important factor to access debt finance (Asah \& Fatoki, 2011). Collateral of assets is essentially necessary for SMEs to enable them to borrow and also block any gaps that exist between lender and borrower (Nawi, 2015). MSEs face difficulties to access external credit because they lack of assets to be pledged as collateral (Balogun, Agumba, \& Ansary, 2016; Kira \& He, 2012) and hardly meet the lenders' requirement of collaterals (Hoang \& Otake, 2014). In Ethiopia, lack of collateral is key challenges to access loan by MSEs from financial institutions (MoUDH, 2016; Mohammed, Tsehai, Abebe, Tekle, Derbie, \& Degefa, 2015). MSE faces difficulty of submitting collateral required by MFIs (Assefa, Zerfu, \& Tekle, 2014; Tadesse, 2014). The study by (Abdesamed \& Wanab, 2014) found collateral is negatively related to access to finance by MSEs in Libya. Also, the study by (Asah \& Fatoki, 2011) found significant positive relationship between collateral and access to debt finance by MESs in South Africa. Similarly, the study by (Kira \& He, 2012) found significant positive association between availability of collateral and accessibility of debt finance by MSEs in Tanzania. Moreover, the study by (Osano \& Languitone, 2016) found a significant relationship between collateral requirements and access to finance by MSEs in Mozambique

The bureaucracy associated with getting loan is another factor that affects access to credit by MSEs and the case is more severe for small MSEs which tend to take out larger loans (Mohammed, Tsehai, Abebe, Tekle, Derbie, \& Degefa, 2015). MSEs are required to fulfill loan delivery pre-conditions (Tadesse, 2014). The credit delivery procedure of MFIs specifies the maximum amount of credit to be provided for MSE considering some preconditions (MoUDH, 2016). To access credit from MFI, MSEs engaged in priority sectors are required to save 20 percent of the loan within six months (MoUDH, 2016; Assefa, Zerfu, \& Tekle, 2014) and MSEs that are neither engaged in export nor in priority sectors are forced to save 25 to 30 percent of their credit need within six months (Assefa, Zerfu, \& Tekle, 2014). The common problems facing MSEs is failing to get the loan they applied for due to very long loan procedure of MFI with repeated delays in loan delivery (Assefa, Zerfu, \& Tekle, 2014).

Goshu (2016) conducted a study on determinants of access to credit and credit source choice by MSEs in Nekemte town using data collected from 173 MSE operators. The binary logistic regression found that the variables firm size, firms owing of business plan, firm location, propensity of risk taking, firm age and prevalence of corruption are statistically significant determinants of access to credit by MSE. Also, analysis of multinomial logit model found that firm size, access to work premises, firm location, business information, firm age, firm capital and prevalence of corruption in loan processing shows statistical significant relationship with credit source choice decision of MSE operators. Similarly, firm size, firm age, corruption and firm locations are significant determinants of access to credit by the MSE operators in Nekemte town.

Menike (2015) conducted a study on the capital structure choices and financing of MSEs in Sri Lanka using data collected from 300 MSEs and analyzed by univariate and multivariate logistic regression model found that age, size, ownership structure, information asymmetry and level of intangible activity are important determinants of the capital structure of MSEs in Sri Lanka. It is evident that when firms become older and larger they accumulate enough fixed assets by eliminating informal asymmetry, they tend to acquire long term loans providing fixed assets as collaterals. The results also reveal that the industry specific effects are important in the context of SME capital structures and MSEs in Metal and Wood industries are less likely to use internal finance while the MSEs in Textile industry are more likely to use long term debts.

Peci (2015) assessed what determines the allowance of bank loans for MSEs using firm and entrepreneurship characteristics of MSE active in international trade towards investment and growth and analyzed data collected 
through self-administered interviews with 180 MSEs in Kosovo. The result of linear regression indicates that a large number of firm and entrepreneur characteristics including experience, sector, business plan, audit statements and collateral significantly affect assess to investment loan by MSEs from banks. The findings of his study also reveals education of MSE managers have higher rate of financing sources through bank loan.

Kira and He (2012) examined the impact of firm characteristics in access to debt financing by Tanzanian MSEs using access to finance as dependent variable and firm characteristics as independent variable in analysis of data collected using self administered questionnaire from 163 Tanzanian MSE firms. The statistical analysis of Pearson correlation and logistic regression indicated that firm's location, industry, size, business information, age, incorporation and collateral are significant factors that influence access to debt finance by MSEs in Tanzanian.

\section{Research Methodology}

\subsection{Research Design}

The study used quantitative research design along with empirical analysis to meet the objective of the study. The research approach consists of primary data collection through the use of questionnaires by survey design.

\subsection{Data Source and Type}

Data used in this study was collected from both primary and secondary sources of data. The researcher collected primary data from MSE's owners operating in Nekemte town. The secondary source is collected from the internet and web sites.

\subsection{Target Population of the Study}

The target population of the study was 2, 295 MSE firms which are operating their business in Nekemte town. The MSE firms used as a population of the study are categorized in to five strata based on Ethiopian government MSE development strategy (MoUDH, 2016) and consider the sector agriculture, construction, manufacturing, service and trade as the priority sector in terms of job creation and revenue generation as shown by the following table. Target population

\begin{tabular}{|l|l|l|}
\hline No & Description & Nekemte town \\
\hline 1 & Manufacturing & 317 \\
\hline 2 & Construction & 406 \\
\hline 3 & Agriculture & 17 \\
\hline 4 & Dairy & 118 \\
\hline 5 & Mineral & 3 \\
\hline 6 & Service & 797 \\
\hline 7 & Trading & 637 \\
\hline & Total & 2,295 \\
\hline
\end{tabular}

Source: Nekemte MSE office, 2017

\subsection{Sampling method and sample size selection}

Sampling is the process of selecting individuals for a study (McMillan and Schumacher, 1999). For the purpose of this study probability sampling techniques by using simple random sampling technique was used to sample the respondents. The total sample size was calculated using Slovin's sampling formula:

$$
\mathrm{n}=\underline{\mathrm{N}} \overline{\left(1+\mathrm{N}\left(\mathrm{e}^{2}\right)\right.}
$$

Where $e$ is the level of precision, i.e., $e=0.075 \mathrm{~N}=$ Population size; and $\mathrm{n}=$ sample size

$=195$ respondents

$$
\mathrm{n}=\left[5,145 /\left(1+5,145 *(0.07)^{2}\right]\right.
$$

\subsection{Method of Data Collection}

This study was based on primary data collection through structured questionnaires that contained closed questions. The questioners are collected through researcher own administration.

\subsection{Description of Variable and Model Specification}

The dependent variable of this study was access to finance (AF) by MSE firm. The dependent variable was examined using binary logistic regression in which access to finance has value of 1 if the MSE firm has accessed formal credit from financial institution and 0 otherwise.

\subsection{Description of variables}

The independent variables of the study includes individual operators owners factors (such as gender, business 
experience, education and basic training), and financing institutions related factors (such as collateral requirement, loan procedures and loan terms) compiled based on the review of previous studies in the areas of determinants of access to finance by MSE firms.

\subsection{Model specification}

This study considers access to credit from the perspective of MSE owners who are operating their business in the study area. The study used binary logistic regression as pervious researchers such as (Balogun, Agumba, \& Ansary, 2016; Goshu, 2016; Menike, 2015; Abdulsaleh \& Worthington, 2013; Nguyen \& Luu, 2013; Kira \& He, 2012) and others used in their research work for estimating determinants of access to finance by MSEs in their respective countries.

The logit model is used to derive determinants of access to credit by ensures that the probability lies in the interval of 0 and 1 (Field, 2009). Access to finance or credit considerer dependent variable, $A F$, with 2 possible outcomes $(1,0)$ in which the expression $\mathrm{AF}=1$ represents an event that a firm has accessed credit and $\mathrm{AF}=0$ represents an event that is not. Binary logistic regression analysis is used for predicting the probability that $A F=1$ for known values of predictor variables $X_{1}, \cdots, X_{k}$. The technique enables us to identify the most influential predictor variables affecting access to credit $(\mathrm{AF}=1)$. In binary logistic regression, the dependent variable $\mathrm{AF}$ is defined as follows:

$$
\mathrm{AF}=\left\{\begin{array}{c}
1 \text { if the MSE firms are accessed formal credit } \\
0 \text { otherwise or MSE firms not accessed credit }
\end{array}\right.
$$

Generally, the binary logistic regression of dichotomous outcome variable AF on the combination of $\mathrm{k}$ discrete and continuous independent variables $X_{1} X_{2}, \ldots \ldots, X_{k}$ is defined by the following logit function:

$$
\operatorname{logit}\left(P_{i}\right)=\operatorname{In}\left(\frac{P_{i}}{1-P_{i}}\right)=\hat{\beta}_{0}+\hat{\beta}_{1} X_{1}+\hat{\beta}_{2} X_{2}+\cdots+\hat{\beta}_{k} X_{k}
$$

The probability of MSE accessed formal credit is given by the statistical expressions:

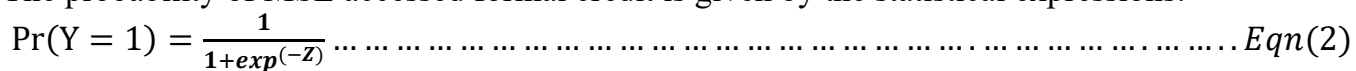

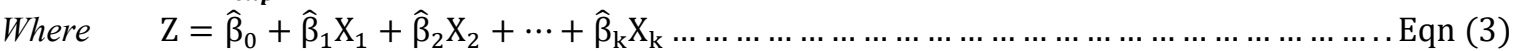

Using equation (3), the probability of $A F=1$ (the probability of MSE firm credit participation), given the values contributing variables for access to credit by the MSE firms $X_{1}, X_{2}, \ldots \ldots, X_{k}$, can be done for any randomly selected MSE firm in this study.

\section{Results and Discussions}

\subsection{Demographic characteristics of study participants}

The first part of the questionnaire was designed to gather information about employees' characteristics. In line with the survey questionnaires, the result of the study shows that $139(69.7 \%)$ of the respondents were male whereas $56(30.3 \%)$ of the study participants were female. The study result shows most of the study participants are male $(69.7 \%)$ indicating access to finance was not as much a problem as stated by (Asah \& Fatoki, 2011) in which the gender of the MSE owner may affect the capital structure choice of the firm where women owned businesses are less likely to use debt financing.

When the highest educational status of the study participants is considered, the result of the study on table 4 shows that $84(40.0 \%)$ of the study participants were high school complete in academic achievement followed by $65(35.1 \%)$ of them with elementary level of school achievements. The result of the study also shows that $39(21.1 \%)$ of respondents were Diploma/TVET complete whereas $4(3.8 \%)$ of the study participants were first degree and above level in their academic achievements. According to (Mahmood, Jaafar, Ibrahim, \& Tajuddin, 2016), the educational level of MSE owner/manager is the key human capital related to the MSE operators' ability to generate higher opportunity for the success of business. But, the result of this study is an evident that 75.1 percent of respondents were elementary and high school complete level of educational achievements that affects the MSE operators' ability for the success of the MSE business. 
Table 4: Demographic characteristics of the study participants

\begin{tabular}{llr}
\hline Characteristic & Variable & Frequency (\%age) \\
\hline Sex of the study participant & Male & $139(69.7 \%)$ \\
& Female & $56(30.3 \%)$ \\
\hline \multirow{3}{*}{ Educational status of the study participant } & Elementary & $65(35.1 \%)$ \\
& High school complete & $84(40.0 \%)$ \\
& Diploma/TVET & $39(21.1 \%)$ \\
& Degree and above & $14(3.8 \%)$ \\
\hline \multirow{3}{*}{ Position/relation of the } & Owner manager & $67(36.2 \%)$ \\
study participant in MSE & Accountant & $49(26.5 \%)$ \\
& Member & $63(34.1 \%)$ \\
& Employee & $6(3.2 \%)$ \\
\hline \multirow{2}{*}{ Initial source of capital } & Own saving & $49(26.5 \%)$ \\
& Informal credit & $67(36.2 \%)$ \\
& Formal credit & $59(31.9 \%)$ \\
The startup capital category of the MSE firms & Iquib & $24(5.4 \%)$ \\
\hline Do the MSE owner acquired basic record & Yes & $167(90.3 \%)$ \\
keeping training & $1000-50,000$ Birr & $11(5.9 \%)$ \\
\hline
\end{tabular}

Source: Own survey, 2018

Similarly, regarding the status or positions of the study participants in the MSE, the result of the study on table 4 shows that $67(36.2 \%)$ of respondents were owner manager of the MSE business followed by 63(34.1\%) of respondents were MSE operators that are working as members in the MSE firm. The result of the study also shows $49(34.1 \%)$ of the MSE owners are working in the position of accountant whereas the remaining $6(3.2 \%)$ of the study participants were salary based employed MSE operators working in MSE firm. The result of the study was an evident that almost all (96.8\%) of the study participants were owners of the MSE firms.

Moreover, when the initial source of startup capital used by the study participants is considered, the study result on table 4 shows $67(36.2 \%)$ of respondents were used informal credit to start their MSE followed by $59(31.9 \%)$ of respondents that used credit from formal sources of finance. The study result also shows that $49(26.5 \%)$ of respondents used own personal saving to launch their MSE business and the remaining 10(5.4\%) of respondents used Iquib as a startup capital for MSE firm. Similarly, the study shows 167 (90.3\%) of respondents started their MSE business with capital found in the range of 1,000 to 50,000 Birr followed by $11(5.9 \%)$ of study participants that started MSE operation with capital that ranges from 50,001 to 100,000 Birr and the remaining $7(3.8 \%)$ of them started business that ranges from 100,001 to 500,000 Birr. The study result indicates 68.1 percent of respondents used informal source of capital to start MSE due to lack of access to credit. This is supported by the work of (Mohammed, Tsehai, Abebe, Tekle, Derbie, \& Degefa, 2015) that states MSE firm start business by informal sources acquired from families, friends and social institutions including Iqubs for their MSE firm.

Finally, when the issue of basic record keeping training participation by members of the MSE firms were considered, the result of the study on table shows that $69(37.3 \%)$ of the study participants were acquired basic record keeping training whereas $116(62.7 \%)$ of the study participants were not get any basic record keeping training. According to (Legas, 2015), lack of entrepreneurial training is an emerging critical challenge to MSE entrepreneurs in Sub-Saharan African counties. Lack of record keeping training was also visible in the result of this study since there were only 37.3 percent of respondents that have acquired basic record keeping training.

\subsection{The MSE operators related determinants of access to finance}

The personal characteristics of the MSE firm owners such as age, education, experience and skills make a significant difference to the firm's ability of accessing external finance (Noumigue, 2015; Nguyen \& Luu, 2013). In line with this, the result of the study on table 8 was an evident that 20(10.8\%) of the respondents strongly agree that MSE managers/operators found in the age category of 25-45 years old were better manage MSE firm whereas $13(7.0 \%)$ of respondents strongly disagree whether MSE managers/operators found in the age category of 25-45 years old were better manage MSE firm. Also, the study shows that 51(27.6\%) of respondents agree that MSE managers/operators found in the age category of 25-45 years old were better manage MSE firm whereas 34(18.4\%) of respondents disagree whether MSE managers/operators found in the age category of 25-45 years old were better manage the MSE firm. Similarly, the study shows that 67(36.2\%) of respondents were indifferent whether MSE managers/operators found in the age category of 25-45 years old were better manage the MSE firm that enhance assess to finance. 
Table 8: MSE firm operators related determinants of access to finance

\begin{tabular}{llr}
\hline Characteristic questions & Variables & Frequency (\%age) \\
\hline Managers/operators found in the age category & Strongly disagree & $13(7.0 \%)$ \\
of 25-45 years old were better manage MSE & Disagree & $34(18.4 \%)$ \\
firm & Neutral & $67(36.2 \%)$ \\
& Agree & $51(27.6 \%)$ \\
& Strongly agree & $20(10.8 \%)$ \\
\hline Experienced operator easily access credit from & Strongly disagree & $15(8.1 \%)$ \\
financial institutions than others & Disagree & $35(18.9 \%)$ \\
& Neutral & $69(37.3 \%)$ \\
& Agree & $48(25.9 \%)$ \\
& Strongly agree & $18(9.7 \%)$ \\
\hline Business plan knowledge by the MSE owner & Strongly disagree & $14(7.6 \%)$ \\
enhances access to finance & Disagree & $32(17.3 \%)$ \\
& Neutral & $64(34.6 \%)$ \\
& Agree & $45(24.3 \%)$ \\
& Strongly agree & $30(16.2 \%)$ \\
\hline
\end{tabular}

Source: Own survey, 2018

Also, regarding the perception of respondents whether educated and experienced operator easily access credit from financial institutions than others in the MSE firms, the result of the study on table 8 shows that 18(9.7\%) of respondents strongly agree that educated and experienced operator easily access credit from financial institutions than others whereas $15(8.1 \%)$ of study participants strongly disagree that educated and experienced operator easily access credit from financial institutions than others in the MSE firm. Also, the study shows that 48(25.9\%) of respondents agree that educated and experienced operator easily access credit from financial institutions than others whereas $35(18.9 \%$ ) of respondents disagree whether educated and experienced operator easily access credit from financial institutions than others in the MSE firms. Similarly, the result of the study shows that $69(37.3 \%)$ of respondents were indifferent whether educated and experienced operator easily access credit from financial institutions than others in the MSE firms in the study area.

Finally, with respect to the perception of respondents whether business plan knowledge by MSE owner enhances access to finance by the MSE firm was considered, the result of the study on table 8 reveals that 30(16.2\%) of the respondents strongly agree that business plan knowledge by MSE owner enhances access to finance by the MSE firm whereas $14(7.6 \%)$ of respondents strongly disagree that business plan knowledge by MSE owner enhances access to finance by the MSE firm. Also, the result of the study shows that $45(24.3 \%)$ of respondents agree that business plan knowledge by MSE owner enhances access to finance by the MSE firm whereas 32(17.3\%) of respondents disagree that business plan knowledge by MSE owner enhances access to finance by the MSE firm. Finally, the study result shows $64(34.6 \%)$ of respondents were indifferent whether business plan knowledge by MSE owner enhances access to finance by the MSE firm.

\subsection{Financing institution related determinants of access to finance}

Microfinance institutions (MFIs) are organizations that provide micro financing services for MSE owners that lack access to formal banking services due to lack of financial or physical collateral (IMF, 2016). Under this, the credit financing availability from MFIs for MSE firms, perception of respondents on the supply of financing for borrower, loan processing procedures of MFIs and whether the MSEs operators get the required loan size from MFIs for the MSE firms. 
Table 11: Financing institution related determinants of access to finance

\begin{tabular}{llr}
\hline Characteristic questions & Variables & Frequency (\%oage) \\
\hline Credit financing from MFI is easily available & Strongly disagree & $78(42.2 \%)$ \\
for the MSE firms & Disagree & $57(30.8 \%)$ \\
& Neutral & $34(18.3 \%)$ \\
& Agree & $9(4.9 \%)$ \\
& Strongly agree & $7(3.8 \%)$ \\
\hline Loan lenders found in Nekemte are sufficient & Strongly disagree & $29(15.7 \%)$ \\
enough to fulfill the demand of MSE & Disagree & $76(41.1 \%)$ \\
borrowers & Neutral & $54(29.2 \%)$ \\
& Agree & $17(9.2 \%)$ \\
& Strongly agree & $9(4.9 \%)$ \\
\hline The loan processing procedures of MFI is & Strongly disagree & $6(3.2 \%)$ \\
difficult and time consuming for MSE firms & Disagree & $18(9.7 \%)$ \\
& Neutral & $37(20.0 \%)$ \\
& Agree & $78(42.2 \%)$ \\
The MSE owners can get the requested loan & Strongly agree & $46(24.9 \%)$ \\
size from MFI without any limitation & Disagree & $83(44.9 \%)$ \\
& Neutral & $70(37.8 \%)$ \\
& Agree & $17(9.2 \%)$ \\
& Strongly agree & $9(4.9 \%)$ \\
& & $6(3.2 \%)$ \\
\hline
\end{tabular}

Source: Own survey, 2018

When the perception of the respondents whether credit financing from MFIs is easily available for the MSE firms, the result of the study on table 11 reveals that $7(3.8 \%)$ of respondents strongly agree that credit financing from MFIs is easily available for MSE firm whereas $78(42.2 \%)$ of respondents strongly disagree on the fact that credit financing from MFIs is easily available for MSE firm. Also, the study shows that 9(4.9\%) of respondents agree that credit financing from MFIs is easily available for MSE firms whereas 57(30.8\%) of respondents disagree on the fact that MSE credit financing from MFIs is easily available for MSE firms and the remaining 34(18.3\%) of respondents were indifferent whether credit financing from MFIs is easily available for MSE firms in Nekemte town.

Also, with respect to the perception of respondents on the issue of loan lenders found in Nekemte are sufficient enough to fulfill the demand of MSE borrowers, the result of the study on table 11 shows that $18(9.7 \%)$ of respondents strongly agree that loan lenders found in Nekemte were sufficient enough to fulfill the demand of MSE borrowers whereas $15(8.1 \%)$ of respondents strongly disagree that loan lenders found in Nekemte were sufficient enough to fulfill the demand of MSE borrowers. Also, the study shows that $48(25.9 \%)$ of respondents agree that loan lenders found in Nekemte are sufficient enough to fulfill the demand of MSE borrowers whereas $35(18.9 \%)$ of respondents disagree that loan lenders found in Nekemte were sufficient enough to fulfill the demand of MSE borrowers. Similarly, the result of the study shows that $69(37.3 \%)$ of respondents were indifferent whether loan lenders found in Nekemte were sufficient enough to fulfill the demand of MSE borrowers in the study area.

Similarly, regarding the perception of respondents whether the loan processing procedures of MFIs was difficult and time consuming for MSE firms, the result of the study on table 11 shows that $46(24.9 \%)$ of respondents strongly agree that loan processing procedures of MFIs were difficult and time consuming for MSE firms whereas $6(3.2 \%)$ of respondents strongly disagree that loan processing procedures of MFIs was difficult and time consuming for MSE firms. Also, the study shows that $78(42.2 \%)$ of respondents agree that loan processing procedures of MFIs was difficult and time consuming for MSE firms whereas $18(9.7 \%)$ of respondents disagree that loan processing procedures of MFIs was difficult and time consuming for MSE firms. Similarly, the result of the study shows that $37(20.0 \%)$ of respondents were indifferent whether loan processing procedures of MFIs was difficult and time consuming for MSE firms.

Finally, with respect to the perception of respondents whether MSE owners can get the requested loan size from MFIs without any limitation for the MSE firms, the result of the study on table 11 reveals that $6(3.2 \%)$ of respondents strongly agree that MSE owners can get the requested loan size from MFIs without any limitation for the MSE firms whereas $83(44.9 \%)$ of respondents strongly disagree on the fact that MSE owner can get the requested loan size from MFIs without any limitation for the MSE firms. Also, the result of the study shows that 9(4.9\%) of respondents agree that MSE owner can get the requested loan size from MFIs without any limitation for the MSE firms whereas 70(37.8\%) of respondents disagree on the fact that MSE owners can get the requested loan size from MFIs without any limitation for the MSE firms and the remaining 17(9.2\%) of respondents were indifferent whether MSE owners can get the requested loan size from MFIs without any limitation for the MSE 
firms in Nekemte.

\subsection{Logistic regression analysis}

Logistic regression is useful for the situations in which the dependent variable is dichotomous (Bryman \& Cramer, 2005). Binary logistic regression is used to explain the relationship between dichotomous dependent variable (yes, no) and several determinants factors (Garson, 2012). The relationship between access to finance by the MSE firm and predictor variables with binary outcome dependent variable can successfully be explained by using the binary logistic regression model. Access to finance by the MSE firm is dichotomous outcome variable with only two possible values ( 1 if the MSE firm accessed finance and 0 otherwise). The value of 1 indicates that the MSE firms have accessed credit from MFIs for the MSE firm and the value 0 indicates that the MSE firms have not accessed credit from MFIs in the study. For convenience, the collected data entered in to SPSS version 20 was transferred in to STATA soft ware version 10 for the analysis of binary logistic regression.

However, before conducting logistic regression, the problem of multicollinearity was tested. Multicollinearity in the logistic regression analysis is the critical problem (Field, 2009). The problem of multicollinearity in the variable was detected by using Variance Inflation Factor (VIF) and tolerance limit. As a rule of thumb, the value of VIF has to be less than 4 and the tolerance limit has to be above 0.2 cut off point (Garson, 2012). To access the existence of multicollinearity problem among the independent variables, the correlation between independent variables was obtained using the command VIF after regression. The result of the study shows that the mean value of VIF for all independent variables was 1.32 with the highest value of 1.8 observed on the number of members in MSE firm variable. Also, the study shows that the value of tolerance (1/VIF) was above 0.2 cut off point with the minimum value of 0.555 observed on the number of member in the MSE firm variable (Annex 2).

The binary logistic regression model estimates by the command logistic presents the output coefficients of the independent variables measured in odds ratios (Field, 2009). In binary logistic regression, influential predicator variables are characterized by odds ratios that are significant at $\mathrm{P}$-values of smaller than 0.05 , at 5 percent level of significance. The P-values from the $\log$ likelihood ratio is equal to $0.0000<0.05$. This shows that 12 predictor variables constituting the fitted logistic regression model were jointly significant in explaining access to finance by 185 MSE firms. The proportion of the explained variations of the fitted value of the model was equal to 51.14 percent that shows the fitted model is reliable for the analysis (annex 3). But, determinants of access to finance by MSE firms are analyzed by using the value of marginal effect computed after logistic regression with the command $m f x$ that describes in terms of predicted probability (annex 4).

A total of 12 explanatory variables were considered in the binary logistic regression model. The results indicated that 6 out of 12 variables used were statistically significant at 1 percent and 5 percent significance level to influence access to finance by the MSE firm in Nekemte town. The variables that significantly affects access to finance by the MSE firm includes: educational level of the MSE firm owner, the MSE firm stages of growth, record keeping practice of the MSE firm, the effect of educational status of MSE operators, potential lenders fond in Nekemte at 5 percent significance level whereas the initial source of the MSE firm startup capital of the MSE firm shows a significant effect on access to finance by the MSE firm at 5percent significance level. The marginal effect of the likelihood of access to finance by the MSE firm is summarized by table 14 and the detail result of the study is described by annex 4 of this study.

Education level of study participants (EDCN): Educational level of the study participants positively influenced the likelihood of access to finance by the MSE firms at 5 percent significant level. A change from elementary level of educational achievements from the mean of 1.935 to high school level of educational achievements by the MSE operators increased the likelihood of access to finance by the MSE firms by 8.93 percent. Also, a change from high school level of educational achievements from the mean of 1.935 to Diploma/TVET level of educational achievements by the MSE operators increased the likelihood of access to finance by the MSE firms by 8.93 percent. The study also indicates a change from Diploma/TVET level of educational achievements from the mean of 1.935 to Degree and above level of educational achievements by the MSE operators increased the likelihood of access to finance by the MSE firms by 8.93 percent. This implies as the educational level of the MSE owners increase from lower to higher level, the likelihood of access to finance by MSE firm MFIs also increases. The result of this study was supported by the work of (Nguyen \& Luu, 2013) that found educational level of the owner/ manager measured by primary, secondary and tertiary education significantly impact the ability to borrow from formal sources by MSEs in Viet Nam. 
Table 14: Marginal effect of binary logistic regression on access to finance

\begin{tabular}{|c|c|c|c|c|c|c|c|}
\hline $\begin{array}{l}\text { Determinants of access to } \\
\text { finance variables }\end{array}$ & $d y / d x$ & $\begin{array}{l}\text { Std. } \\
\text { Err. }\end{array}$ & $\mathbf{z}$ & $\mathbf{P}>\mathbf{z}$ & $\begin{array}{l}{[95 \%} \\
\text { Conf. }\end{array}$ & Interval] & $\begin{array}{l}\text { Mean }(x) \\
\text { variable }\end{array}$ \\
\hline Sex of the respondent $\left(\mathrm{SEX}^{*}\right)$ & .049786 & .08277 & 0.60 & 0.547 & -.112434 & 212005 & 0.697297 \\
\hline Educational level (EDCN) & .0893802 & .0456 & 1.96 & $0.050^{*}$ & $7.7 \mathrm{e}-07$ & 17876 & 1.935114 \\
\hline Sector of the MSE firm & -.0351208 & .02545 & -1.38 & 0.168 & -.084998 & .014756 & 3.46486 \\
\hline (MSIAGI & 547 & .07424 & 2.08 & $0.037 *$ & .009257 & & 1.40541 \\
\hline of memb & -.1032 & .09254 & -1.12 & 0.256 & -284635 & & 1351 \\
\hline E) & .336 & .05611 & 5.9 & 0.00 & 226282 & & 216 \\
\hline pital & -.0440 & 03962 & -1.11 & 0.266 & -.121681 & & 108 \\
\hline & & .06 & & & & & \\
\hline & & & & & & & \\
\hline is (LOT & -2091418 & .1094 & -1.91 & 0.056 & -.423562 & .005279 & 0.751351 \\
\hline Pote & -.0964349 & .04207 & -2.29 & $0.022 *$ & -.178884 & 986 & 3.51351 \\
\hline Loan procedure of MFIs & -.0429095 & .03326 & -1.29 & 0.197 & -.108094 & .022275 & .3 .75676 \\
\hline $\begin{array}{l}\text { Number of obs }=185 \\
\text { LR chi2 } 2(12)=122.02\end{array}$ & & 5820 & & & & & \\
\hline
\end{tabular}

** \& * indicates the significance level of variables at 1percent and 5 percent respectively

$\left.{ }^{*}\right) \mathrm{dy} / \mathrm{dx}$ is for the discrete change of dummy variable from 0 to 1

Source: Computation from survey data, 2018

The MSE stage of growth (MSTAGE): The second significant determinant of access to finance by the MSE firm is the growth stage of MSE firm. The MSE growth stage is measured by the change from micro enterprise to small enterprise Level of the MSE firm or the change from the small enterprises to medium enterprise level of the MSE firms. The growth stage of the MSE firm positively influenced the likelihood of access to finance by the MSE firm at 5 percent significant level. A change in micro enterprise level of MSE firm from the mean of 1.40 to small enterprise level of the MSE firm increased the likelihood of assess to finance of the MSE firm by 15.47 percent. Logically, the significant positive effect of the MSE stage of growth on access to finance implies access to finance by the MSE firm is affected by the size of MSE firm in which small enterprises have more access than micro enterprise since small enterprise have high size opportunity in terms MSE capital and number of members than micro enterprise. The finding is supported by (Mohammed, Tsehai, Abebe, Tekle, Derbie, \& Degefa, 2015) that found small enterprises are more likely to have accessed loans than micro enterprises. Also, a change in small enterprise from the mean of 1.40 to medium enterprise level increased the likelihood of assess to finance of MSE firm by 15.47 percent indicating medium enterprise have more access to finance than small enterprise since medium enterprises have better size opportunity in terms of MSE firm capital and number of members than small enterprises. The result of this is in line with the work of (Menike, 2015) that firm size is a significant determinant of access to finance by the MSE in Sri Lanka. Also, the result of the study is in line with the work of (Nawi, 2015) that found firm size significantly affects access to finance by the MSE firms in Malaysia.

Initial sources of MSE startup capital (ISORCE): The initial sources of the MSE firm startup capital is the third significant determinant variable that positively influenced access to finance by the MSE firms in this study. The initial sources of the MSE firm startup capital is measured in by personal saving of the members, informal sources of credit from friends/relatives and formal credit from financial institutions like MFIs to start the MSE business operation. The initial sources of startup capital used by the MSE firm positively influenced the likelihood of access to finance by the MSE firm at 1 percent significant level. A change from personal saving source of startup capital of the MSE firm from the mean of 2.16 to informal sources of startup credit increases the likelihoods of access to finance by the MSE firm by 33.63 percent. Also, a change from informal sources of startup capital from the mean of 2.16 to formal sources credit for startup by the MSE firm increases the likelihoods of access to finance by the MSE firm by 33.63 percent. The change in sources of startup capital from personal saving to informal sources of credit for startup or the change from informal sources of credit to formal sources of credit for startup capital increases the likelihood of access to finance by the MSE firms. This implies MSE firms used informal credit has more practice in accessing credit than MSE firms started with personal saving as well as MSE firms that begun by formal sources of credit have more practice in accessing formal credit than MSE firms started by personal saving and informal sources of credit. This is supported by $(\mathrm{MoUDH}, 2016)$ that stated lack of experience in using credit is the most critical constraints to MSE in Ethiopia. Also, the study is supported by (Kira \& He, 2012) that found MSE firms at the early stage of operation used to experience difficulties in access to debt finance because of informational disparities.

The record keeping practice of the MSE firm (RECKEEP): The recordkeeping practice of the MSE firm is another significant determinant variable that positively influenced access to finance by the MSE firms that is 
measured in terms of lack of record for the MSE, keeping minimum record about the MSE firm and keeping formal records of the MSE firms. The recordkeeping practice about the MSE firm positively affected access to finance by the MSE firms at 5 percent significance level. A change in lack of record for the MSE business from the mean of 1.70 to minimum financial record keeping practice increases the likelihoods of access to finance by the MSE firm by 13.37 percent. Also, a change in minimum financial records keeping practice from the mean of 1.70 to formal financial records keeping practice increases the likelihoods of access to finance by the MSE firm by 13.37 percent. This Implies financial institutions relay on the record of the MSE firm in the provision of credit indicating MSE that have keep financial record are more likely to access to finance from MFIs in the study area. This is supported by (Nawi, 2015) that stated the practice of keeping financial records of MSE firm reduce the problem of information asymmetries and enjoy better access to debt financing. Also, this is in line with the work of (Nguyen \& Luu, 2013) that found having accounting records significantly impact the ability to borrow from formal sources of finance by MSEs in Viet Nam.

The MSE operators' education affects access to finance (OEDCN): This is the perception of study participants' information on the effect of MSE operators' education on access to finance by the MSE firm. The result of this study revealed that MSE operators' education negatively influenced the likelihood of access to finance by the MSE firm at 5 percent significant level. A change in lack of information on the effect MSE operators' education from the mean of 0.77 to owning of information on the effect MSE operators' education on access to finance decreases the likelihoods of access to finance by the MSE firm by 25.44 percent. The change in the perception of respondents from lack of information to possessing information whether the MSE operators' education affects access to finance will make the MSE operators less likely to assess finance from formal financial institutions by the MSE firms. The result of this study similar to the work of (Menike, 2015) that found information asymmetry is an important significant determinant of access to finance by the MSE firms in Sri Lanka.

Awareness about potential lenders (POLEND): Respondents awareness about potential lenders of the MSE firm is also another significant determinant of access to finance by the MSE firms. The MSE firm operators awareness about potential lenders found in the study area are measured by participants lack of awareness about any lenders, having awareness about banks as potential lender, having awareness about MFIs as potential lender, having awareness about banks and MFIs as potential lender, and having awareness about banks, MFIS and relatives as the potential lenders in the study area. The result of the study shows that MSE operators' awareness about potential lenders for the MSE firm negatively influenced access to finance by the MSE firms at 5 percent significance level. A change in having few level of awareness about potential lenders from the mean of 3.51 to having more diverse level of awareness about the potential lenders for the MSE firms decreases the likelihoods of access to finance by the MSE firm by 9.64 percent. The result of this study is consistent with the work of (Osano \& Languitone, 2016) that found significant relationship between awareness of funding institutions and access to finance by the MSE firms in Mozambique.

\subsection{Conclusion}

There are diverse determinants of access to finance by the MSEs observed from individual MSE operators, from MSE firm, from management performance and from the sides of MSE firm financing institutions. These determinants of access to finance by the MSE from individual MSE operators includes educational level, basic training acquired, operators age of 25 to 45 and operators experience. Firm related determinants of access to fiancé are the sage of MSE growth, numbers of members in the MSEs, initial sources of startup capital and the increased demand of MSE product. MSE management performance related determinants of access to finance includes record keeping practice, business planning knowledge and awareness about potential lenders found in Nekemte town. Finally, financing institutions related determinants of access to finance by the MSE includes MFI loan term, ease of accessing credit from MFIs and acquiring the requested loan size from MFIs. They were not the sole factors that determine access to finance. The finding of this study was in line with existing literature and studies that was conducted by other earlier researchers' both within the country and outside of the country. However, considering and solving these determinants require the collaborative effect of the different stakeholders and the active participation of the MSE firm owners/mangers.

\subsection{Recommendations}

The nature of determinants of access to finance identified were varying in their complexity and severity that need the collaborative effort of organizations commitment along with the concern of the MSE service providers. The major recommendations suggested by the researcher for mitigating determinants of access to finance were described as follows;

* The management of MSE firms were advised to arrange experience sharing from similar business found in Nekemte town;

* The management of MSE firms were advised to encompass large number of members or operators in their MSE firms as much as possible; 
* The MSE firm owners/mangers were advised to produce a product/services demanded by the community in their MSE business operation;

* The MFIs that deliver credit for MSE firms were advised to be flexible on their loan terms for the MSE firm borrowers in the study area.

* The MFIs were advised to minimize loan processing procedures for MSE firms.

* Finally, MFIs were advised to deliver the requested loan size for the MSE firms.

\section{Reference}

Garson, D. (2012). Testing Statistical Assumptions: Blue Book Series 2012 Edition. USA: Statistical Publishing Associates.

Goshu, F. (2016). Determinants of Access to Credit and Credit Source Choice by Micro, Small and Medium Enterprises in Nekemte, Ethiopia. International Journal of African and Asian Studies, An International Peerreviewed Journal , 28, 11-27.

Habtamu, L. (2015). Challenges to Entrepreneurial Success in Sub-Saharan Africa:A Comparative Perspective. European Journal of Business and Management, 7 (11), 23-35.

Hoang, N. A., \& Otake, T. (2014). Credit Participation and Credit Source Selection of Vietnam Small and medium enterprises. The South East Asian Journal of Management, 8 (2), 104-128.

Inoti, J. M., \& Mbura, L. K. (2017). Effect of Entrepreneurial Marketing on Performance of Real Estate Enterprises: A case of Optiven Limited in Nairobi, Kenya. International Academic Journal of Innovation, Leadership and Entrepreneurship , 2 (1), 46-70.

Kothir, C. (2004). Research Methodology: Methods and Techniques . New Delhi: New Age International Ltd Publisher.

Kusi, A., Opata, h. N., \& Narh, T.-W. J. (2015). Exploring the Factors That Hinder the Growth and Survival of Small Businesses in Ghana: A Case Study of Small Businesses within Kumasi Metropolitan Area. American Journal of Industrial and Business Management , 5, 705-723.

Legas, H. (2015). Challenges to Entrepreneurial Success in Sub-Saharan Africa:A Comparative Perspective. European Journal of Business and Management, 7 (11), 23-35.

Mahadalle, A., \& Kaplan, B. (2017). Entrepreneurial Characteristics and Competencies as Determinants of Corporate Performance: A Study on Small Enterprises in Mogadishu, Somalia. International Journal of Research Granthaalayah, 5 (5), 243-254.

Mahmood, R., Jaafar, H., Ibrahim, N., \& Tajuddin, M. (2016). Managerial Competency: Mediator of Human Capital Development and Micro Enterprises Performance. Journal of Applied Environmental and Biological Sciences , 6 (5S), 55-63.

Menike, L. (2015). Capital Structure \& Financing of Small \& Medium Enterprises: Empirical Evidence from a Sri Lankan Survey. Journal of Small Business and Entrepreneurship Development , 3 (1), 54-65.

Minhle, P. N. (2012). What Determines the Access to Credit by SMEs? A Case Study in Viet Nam. Journal of management research , 4 (4), 90-114.

Mohammed, A., Habtamu, W., \& Dessalegn, B. (2014). Constraints and Growth Potentials of Micro and Small Enterprises: Case from Mekelle City. International Journal of Scientific and Research Publications , 4 (12), $1-7$.

Nguyen, N., \& Luu, N. (2013). Determinants of Financing Pattern and Access to Formal -Informal Credit: The Case of SMEs in Viet Nam. Journal of Management Research, 5 (2), 240-259.

Noumigue, R. K. (2015). Formal, Informal and Semi-Formal Sources of Finance: Is There any Difference amongst Cameroonian Small Enterprises and Medium Enterprises? Journal of Entrepreneurship and Innovation Management , 4 (2), 105-122.

Olawale, F. (2014). The Financing Options for New Small and Medium Enterprises in South Africa. Mediterranean Journal of Social Sciences , 5 (20), 748-755.

Osano, H. M., \& Languitone, H. (2016). Factors influencing access to finance by SMEs in Mozambique: case of SMEs in Maputo central business district. Journal of Innovation and Entrepreneurship , 5 (13), 1-16.

Peci, F. (2015). What determines the allowance of bank loans for investment an overview of Kosovo SMEs. International Journal of Innovation and Economic Development , 1 (1), 27-35.

Radzi, K. M., Mohdnor, M. N., \& Ali, S. M. (2017). The Impact of Internal Factors on Small Business Success: A Case of Small Enterprises Under the FELDA Scheme. Asian Academy of Management Journal , 22 (1), $27-55$.

Sekaran, U., \& Bougie, R. (2010). Research Methods for Business: A Skill Building Approach (4 ed.). UK: John Wiley and Sons Ltd.

Tadesse, B. (2014). Access to Finance for Micro and Small Enterprises in Debre Markos Town Ethiopia. Global Journal of Current Research , 2 (2), 36-46.

UNDP. (2015). National Human Development Report 2014 Ethiopia: Accelerating Inclusive Growth for 
Sustainable Human Development in Ethiopia. Addis Ababa, Ethiopia: United Nations Development Programme.

Watson, J. (2001). How to Determine a Sample Size: Tipsheet \#60,University Park, PA: Penn State Cooperative Extension.

Williams, A. (2014). Accelating Entrepreneurship in Africa: Understanding Africa's Challenges to Creating Opportunity-driven Entrepreneurship. Cambridge, Massachusetts: Omidyar Network.

World Bank. (2014). Addis Ababa Spatial Determinants of Growth: Capstone Report. Addis Ababa: George Washington University, Elliott School of International Affairs.

Zemenu, A., \& Mohammed, M. (2014). Determinants of Growth of Micro and Small Enterprises in Ethiopia:A Case of MSEs in Mekelle City, Tigray. International Journal of Advance Research in Computer Science and Management Studies , 2 (6), 149-157. 